\title{
Comprehensive Trabectome Outcomes in Surgery-naive Versus Previously Operated Eyes
}

\author{
Sameh Mosaed \\ University of California, Irvine, Orange County, CA, US
}

DOI: https://doi.org/10.17925/EOR.2018.12.1.50

$\mathrm{T}$ his study aims to compare the results of trabectome surgery between surgery-naiive eyes and eyes that have previously undergone incisional surgery. Prospective data was collected on the first 20 cases of each new trabectome surgeon. This trabectome dataset was used to create two groups of subjects: surgery-naïve eyes versus eyes with prior incisional surgery. A total of 2,051 eyes were included in the study. These two groups were further broken down into the subtype of glaucoma (primary open angle glaucoma, pigmentary, pseudoexfoliation, uveitic and steroid-induced glaucoma). At 12- and 36-months follow up, success rates, intraocular pressure (IOP) reduction and medication usage were compared between the groups using the Tube versus Trabeculectomy Study criteria for defining success. At 36 months, the IOP of the virgin eyes and the previously operated eyes was $16.3 \mathrm{mmHg}$ versus $15.8 \mathrm{mmHg}$, respectively. This difference was not statistically significant $(p<0.05)$. Trabectome outcomes are similar in eyes with a history of prior incisional surgery (including failed glaucoma procedures) compared with those that are surgery-naive.

\section{Keywords}

Trabectome, glaucoma, primary open angle glaucoma, secondary glaucoma, pseudoexfoliation glaucoma, micro incisional glaucoma surgery (MIGS)

Disclosures: Sameh Mosaed has nothing to disclose in relation to this article.

Review Process: Double-blind peer review.

Compliance with Ethics: All procedures were followed in accordance with the responsible committee on human experimentation and with the Helsinki Declaration of

1975 and subsequent revisions. Informed consent was received from the patients involved in this study.

Authorship: All named authors meet the International Committee of Medical Journal Editors (ICMJE) criteria for authorship of this manuscript, take responsibility for the integrity of the work as a whole, and have given final approval to the version to be published.

open Access: This article is published under the Creative Commons Attribution Noncommercial License, which permits any noncommercial

use, distribution, adaptation, and reproduction provided the original author(s) and source are given appropriate credit. (C) The Authors 2018.

Received: 7 June 2018

Accepted: 31 July 2018

Citation: European Ophthalmic Review. 2018;12(1):50-5

Corresponding Author: Sameh Mosaed, University of California Irvine, Gavin Herbert Eye Institute, 850 Health Sciences Drive, Irvine, CA 92697 US.

E:smosaed@uci.edu

Support: No funding was received for

the publication of this article.
Trabecular bypass with the Trabectome ${ }^{\circledR}$ device (NeoMedix, Tustin, CA, US) has been gaining adoption worldwide since its introduction as a micro-incision glaucoma surgery (MIGS) option for many differing types of glaucoma. As with any new surgical procedure, surgeons rely on published data to guide their decision making and patient-selection criteria until they gain adequate individual experience to refine their adoption patterns. The trabectome was initially used on adult patients with open-angle glaucoma in the original trials performed in 2004. ${ }^{12}$ As several dozen peer-reviewed publications have confirmed its safety and efficacy, the last decade has seen the utilisation of trabectome surgery expand over a wide variety of glaucoma subtypes from mild to severe glaucoma. ${ }^{3-6}$ Here, we will review the long-term success rates and intraocular pressure (IOP) reduction profiles in these subtypes to help guide surgeons in optimising patient selection.

\section{Materials and methods}

This is a prospective outcome analysis of patients grouped by glaucoma subtypes with or without prior incisional surgery undergoing trabectome from the Trabectome Study Group Database. All procedures were followed in accordance with the responsible committee on human experimentation and with the Helsinki Declaration of 1975 and subsequent revisions. Informed consent was received from the patients involved in this study.

The multinational trabectome database consists of anonymised data collected prospectively on the first 20 cases of each new trabectome surgeon and includes demographic information as well as IOP as measured by Goldmann applanation tonometry, gonioscopic findings, optic nerve appearance on slit-lamp examination, Humphrey Visual Field results at baseline and following treatment, best corrected visual acuity and any adverse event data.

We analysed the trabectome database and included all patients with at least 1 year of follow up. Patients were classified based on their glaucoma subtypes. Only patients who were diagnosed with primary open-angle glaucoma (POAG), pseudoexfoliation glaucoma (PEX), pigmentary glaucoma, steroid induced glaucoma and uveitic glaucoma were included into this study (the steroid-induced glaucoma group included only ocular steroids: topical and intravitreal). No patients were double counted in the groupings. Patients were separated into two groups based on a history of prior eye surgery (prior incisional surgery versus virgin eyes), excluding laser. The surgery-naive group (virgin eyes) was compared to eyes with a history of any of the following procedures: trabeculectomy (with or without EX-PRESS ${ }^{\circledR}$ shunt [Alcon, Fort Worth, TX, US]), trabeculotomy, aqueous shunt implantation, corneal transplantation, goniotomy, prior trabectome or istent ${ }^{\circledR}$ (Glaukos, San Clemente, CA, US) or other MIGS, or vitreo-retinal surgery.

Applying the same success criteria established by the Tube versus Trabeculectomy (TVT) study, success was defined as IOP of $<21 \mathrm{mmHg}$ and IOP reduction of $20 \%$ from baseline on two consecutive visits and no secondary surgery.? Preoperative and post-operative outcomes were 
Table 1: Baseline characteristics in each glaucoma subgroup

\begin{tabular}{|c|c|c|c|c|c|c|c|}
\hline \multicolumn{2}{|l|}{ Demographics } & $\begin{array}{l}\text { POAG } \\
n=1,641\end{array}$ & $\begin{array}{l}\text { PEX } \\
n=252\end{array}$ & $\begin{array}{l}\text { Pigmentary } \\
\mathrm{n}=69\end{array}$ & $\begin{array}{l}\text { Steroid } \\
n=38\end{array}$ & $\begin{array}{l}\text { Uveitic } \\
n=51\end{array}$ & $\begin{array}{l}\text { Overall } \\
\mathrm{N}=2,051\end{array}$ \\
\hline \multirow[t]{2}{*}{ Age } & Mean \pm SD & $70 \pm 13$ & $75 \pm 10$ & $59 \pm 11$ & $54 \pm 17$ & $55 \pm 20$ & $70 \pm 13$ \\
\hline & Range & $(0,96)$ & $(76,95)$ & $(32,95)$ & $(23,84)$ & $(6,88)$ & $(0,96)$ \\
\hline \multirow[t]{3}{*}{ Gender } & Female & 823 (50.2\%) & $153(60.7 \%)$ & 19 (27.5\%) & $19(50.0 \%)$ & 28 (54.9\%) & 1,042 (50.8\%) \\
\hline & Male & 749 (45.6\%) & 95 (37.7\%) & 48 (69.6\%) & 19 (50.0\%) & 22 (43.1\%) & 933 (45.5\%) \\
\hline & NR & $69(4.2 \%)$ & $4(1.6 \%)$ & $2(2.9 \%)$ & $0(0.0 \%)$ & $1(2.0 \%)$ & 76 (3.7\%) \\
\hline \multirow[t]{7}{*}{ Race } & African American & $83(5.1 \%)$ & 2 (0.8\%) & $0(0.0 \%)$ & $1(2.6 \%)$ & $4(7.8 \%)$ & 90 (4.4\%) \\
\hline & Asian unspecified & $79(4.8 \%)$ & $11(4.4 \%)$ & $3(4.3 \%)$ & $1(2.6 \%)$ & 2 (3.9\%) & $96(4.7 \%)$ \\
\hline & Caucasian & 737 (44.9\%) & 127 (50.4\%) & 47 (68.1\%) & $6(15.8 \%)$ & 17 (33.3\%) & 934 (45.5\%) \\
\hline & Chinese & $27(1.6 \%)$ & $0(0.0 \%)$ & $1(1.4 \%)$ & $0(0.0 \%)$ & $0(0.0 \%)$ & $28(1.4 \%)$ \\
\hline & Hispanic & $73(4.4 \%)$ & $12(4.8 \%)$ & $4(5.8 \%)$ & $3(7.9 \%)$ & 3 (5.9\%) & 95 (4.6\%) \\
\hline & Japanese & 444 (27.1\%) & 77 (30.6\%) & 7 (10.1\%) & $18(47.4 \%)$ & 20 (39.2\%) & $566(27.6 \%)$ \\
\hline & Other & $198(12.1 \%)$ & $23(9.1 \%)$ & $7(10.1 \%)$ & $9(23.7 \%)$ & $5(9.8 \%)$ & $242(11.8 \%)$ \\
\hline \multirow{7}{*}{$\begin{array}{l}\text { Pre-operative } \\
\text { snellen acuity }\end{array}$} & $>20 / 20$ & 81 (4.9\%) & $13(5.2 \%)$ & $0(0.0 \%)$ & $3(7.9 \%)$ & $7(13.7 \%)$ & 104 (5.1\%) \\
\hline & 20/20-20/40 & 803 (48.9\%) & $121(48.0 \%)$ & 45 (65.2\%) & 15 (39.5\%) & 29 (56.9\%) & $1,013(49.4 \%)$ \\
\hline & 20/50-20/70 & 251 (15.3\%) & 31 (12.3\%) & $7(10.1 \%)$ & $1(2.6 \%)$ & $1(2.0 \%)$ & 291 (14.2\%) \\
\hline & 20/80-20/100 & $82(5.0 \%)$ & $14(5.6 \%)$ & $3(4.3 \%)$ & $3(7.9 \%)$ & 3 (5.9\%) & 105 (5.1\%) \\
\hline & $20 / 200-20 / 400$ & $96(5.9 \%)$ & $22(8.7 \%)$ & $3(4.3 \%)$ & $3(7.9 \%)$ & $4(7.8 \%)$ & $128(6.2 \%)$ \\
\hline & $<20 / 400$ & $53(3.2 \%)$ & $11(4.4 \%)$ & $1(1.4 \%)$ & $2(5.3 \%)$ & $2(3.9 \%)$ & 69 (3.4\%) \\
\hline & NR & 275 (16.8\%) & 40 (15.9\%) & $10(14.5 \%)$ & $11(28.9 \%)$ & $5(9.8 \%)$ & 341 (16.6\%) \\
\hline \multirow[t]{4}{*}{ Lens status } & Phakic & $1,108(67.5 \%)$ & $166(65.9 \%)$ & $51(73.9 \%)$ & 19 (50.0\%) & 30 (58.9\%) & $1,374(67.0 \%)$ \\
\hline & Pseudophakic & 458 (27.9\%) & 74 (29.4\%) & $13(18.8 \%)$ & $11(28.9 \%)$ & 17 (33.3\%) & $531(27.9 \%)$ \\
\hline & Aphakic & $7(0.4 \%)$ & $1(0.4 \%)$ & $3(4.3 \%)$ & $0(0.0 \%)$ & $1(2.0 \%)$ & $12(0.6 \%)$ \\
\hline & NR & $68(4.1 \%)$ & $11(4.4 \%)$ & $2(2.9 \%)$ & $8(21.1 \%)$ & $3(5.9 \%)$ & $92(4.5 \%)$ \\
\hline \multirow[t]{2}{*}{ Prior surgery } & Virgin eyes & $1,510(92.0 \%)$ & $236(93.7 \%)$ & 59 (85.5\%) & $38(100.0 \%)$ & $43(84.3 \%)$ & $1,886(92.0 \%)$ \\
\hline & Previously operated eyes & $131(8.0 \%)$ & $16(6.3 \%)$ & $10(14.5 \%)$ & $0(0.0 \%)$ & $8(15.7 \%)$ & $165(8.0 \%)$ \\
\hline \multirow[t]{3}{*}{ Combined surgeries } & Trabectome + phaco & 637 (38.8\%) & 105 (41.7\%) & $21(30.4 \%)$ & $3(7.9 \%)$ & $10(19.6 \%)$ & 776 (37.8\%) \\
\hline & Trabectome only & 977 (59.5\%) & $143(56.7 \%)$ & $43(62.3 \%)$ & $34(89.5 \%)$ & 40 (78.4\%) & $1,237(60.3 \%)$ \\
\hline & Trabectome + other* & $27(1.6 \%)$ & $4(1.6 \%)$ & $5(7.2 \%)$ & $1(2.6 \%)$ & $1(2.0 \%)$ & $38(1.9 \%)$ \\
\hline
\end{tabular}

*Other surgeries include anterior vitrectomy, pars plana vitrectomy, intraocular lens repositioning, pupilloplasty and synechialysis.

$N R=$ not reported; $P E X=$ pseudoexfoliating glaucoma; phaco = phacoemulsification; $P O A G=$ primary open angle glaucoma; $S D=S t a n d a r d$ deviation .

compared with the two-sample Wilcoxon test. Kaplan Meier survival curves plot and Log-rank tests are used to compare survival rates of the two groups. Excel software (Microsoft Word Corp.) and R 2.14.0 were utilised for the data compilation and statistical analysis.

\section{Results}

A total 2,051 cases were analysed, where 1,886 were virgin eyes and 165 had undergone prior incisional surgery. Of the virgin eyes, most of the patients were diagnosed with POAG (80.0\%) and PEX (12.3\%). The demographic comparison of the glaucoma subtypes is summarised in Table 1. A total of 165 (8.0\%) patients had prior surgeries including trabeculectomy, aqueous shunts or other procedures. A total of 193 (9.4\%) patients required secondary surgery. The average IOP and glaucoma medication usage for all glaucoma subtypes are summarised in Table 2, Figure 1 and Figure 2. There was a total of 1,641 patients with POAG, 252 patients with PEX, 69 with pigmentary glaucoma, 38 with steroid-induced glaucoma and 51 with uveitic glaucoma.
At 36 months, intraocular pressure was reduced by $28 \%$ in the POAG group (from $22.5 \pm 7.1$ to $16.3 \pm 3.9 \mathrm{mmHg}$ ), $35 \%$ in the PEX group (from $25.3 \pm 8.8$ to $16.4 \pm 6.4 \mathrm{mmHg}$ ), $36 \%$ in the pigmentary group (from $25.0 \pm 7.7$ to $16.0 \pm 4.4 \mathrm{mmHg}$ ), $49 \%$ in the steroid-induced group (from $30.1 \pm 10.1$ to $15.4 \pm 2.7 \mathrm{mmHg}$ ), and $52 \%$ in the uveitic group (from $29.8 \pm 7.5$ to $14.3 \pm 2.9 \mathrm{mmHg}$ ); $p<0.01$ for all groups. Medication usage was reduced in all groups (Table 2, Figure 1 and Figure 2). The success rate (survival at 36 months) of each group varied from $65 \%$ in the uveitic group to $84 \%$ in the steroid-induced glaucoma group (Table 3 and Figure 3).

When comparing virgin eyes to eyes previously operated on, IOP was reduced by $30 \%$ (from $23.2 \pm 7.7$ to $16.3 \pm 4.2 \mathrm{mmHg}$ ) and $33 \%(23.7 \pm 7.0$ to $15.8 \pm 4.7 \mathrm{mmHg}$; $p<0.01)$, respectively. Medication usage reduced by $26 \%$ in virgin eyes compared to $31 \%$ in previously operated eyes ( $p<0.01$ for both) (Table 2, Figure 4 and Figure 5). The success rate (survival at 36 months) was statistically significantly 
Table 2: Intraocular pressure and glaucoma medication

\begin{tabular}{|c|c|c|c|c|c|}
\hline Time & $\begin{array}{l}\text { IOP } \\
\text { Mean } \pm \text { SD }\end{array}$ & $\mathrm{p}$-value & $\begin{array}{l}\mathrm{RX} \\
\text { Mean } \pm \mathrm{SD}\end{array}$ & p-value & $\mathrm{n}$ \\
\hline \multicolumn{6}{|c|}{ All glaucoma sub types } \\
\hline Baseline & $23.2 \pm 7.6$ & & $2.7 \pm 1.3$ & & 2,051 \\
\hline 12 months & $15.9 \pm 4.0$ & $<0.01^{*}$ & $2.0 \pm 1.4$ & $<0.01^{*}$ & 1,858 \\
\hline 36 months & $16.3 \pm 4.2$ & $<0.01^{*}$ & $2.0 \pm 1.2$ & $<0.01^{*}$ & 552 \\
\hline \multicolumn{6}{|c|}{ Primary open angle glaucoma } \\
\hline Baseline & $22.5 \pm 7.1$ & & $2.6 \pm 1.3$ & & 1,641 \\
\hline 12 months & $15.9 \pm 3.9$ & $<0.01^{*}$ & $2.0 \pm 1.3$ & $<0.01^{*}$ & 1,481 \\
\hline 36 months & $16.3 \pm 3.9$ & $<0.01^{*}$ & $1.9 \pm 1.2$ & $<0.01^{*}$ & 441 \\
\hline \multicolumn{6}{|c|}{ Pseudoexfoliating glaucoma } \\
\hline Baseline & $25.3 \pm 8.8$ & & $3.0 \pm 1.3$ & & 252 \\
\hline 12 months & $15.3 \pm 4.3$ & $<0.01^{*}$ & $2.1 \pm 1.4$ & $<0.01^{*}$ & 238 \\
\hline 36 months & $16.4 \pm 6.4$ & $<0.01^{*}$ & $2.0 \pm 1.3$ & $<0.01^{*}$ & 66 \\
\hline \multicolumn{6}{|c|}{ Pigmentary glaucoma } \\
\hline Baseline & $25.0 \pm 7.7$ & & $2.9 \pm 1.2$ & & 69 \\
\hline 12 months & $16.8 \pm 5.0$ & $<0.01^{*}$ & $2.2 \pm 1.4$ & $<0.01^{*}$ & 63 \\
\hline 36 months & $16.0 \pm 4.4$ & $<0.01^{*}$ & $1.8 \pm 1.0$ & 0.16 & 24 \\
\hline \multicolumn{6}{|c|}{ Steroid-induced glaucoma } \\
\hline Baseline & $30.1 \pm 10.1$ & & $3.6 \pm 1.1$ & & 38 \\
\hline 12 months & $16.0 \pm 3.5$ & $<0.01^{*}$ & $2.4 \pm 1.5$ & $<0.01^{*}$ & 34 \\
\hline 36 months & $15.4 \pm 2.7$ & $<0.01^{*}$ & $2.4 \pm 1.3$ & $0.02^{*}$ & 11 \\
\hline \multicolumn{6}{|c|}{ Uveitic glaucoma } \\
\hline Baseline & $29.8 \pm 7.5$ & & $3.9 \pm 0.9$ & & 51 \\
\hline 12 months & $16.2 \pm 4.3$ & $<0.01^{*}$ & $2.7 \pm 1.5$ & $<0.01^{*}$ & 42 \\
\hline 36 months & $14.3 \pm 2.9$ & $<0.01^{*}$ & $2.1 \pm 1.2$ & $0.01^{*}$ & 10 \\
\hline \multicolumn{6}{|c|}{ Virgin eye group (eyes with no prior surgery) } \\
\hline Baseline & $23.2 \pm 7.7$ & & $2.7 \pm 1.3$ & & 1,886 \\
\hline 12 months & $15.8 \pm 3.9$ & $<0.01^{*}$ & $2.0 \pm 1.4$ & $<0.01^{*}$ & 1,713 \\
\hline 36 months & $16.3 \pm 4.2$ & $<0.01 *$ & $2.0 \pm 1.2$ & $<0.01^{*}$ & 506 \\
\hline \multicolumn{6}{|c|}{ Previously operated eye group (eyes with prior surgery) } \\
\hline Baseline & $23.7 \pm 7.0$ & & $2.9 \pm 1.2$ & & 165 \\
\hline 12 months & $16.2 \pm 5.0$ & $<0.01^{*}$ & $2.3 \pm 1.4$ & $<0.01^{*}$ & 145 \\
\hline 36 months & $15.8 \pm 4.7$ & $<0.01^{*}$ & $2.0 \pm 1.2$ & $<0.01^{*}$ & 46 \\
\hline
\end{tabular}

*values that are statistically significant. Wilcox test was performed to compare IOP and glaucoma medication usage on different follow-up time with baseline. Significance level was set as $p<0.05 .1 O P=$ intraocular pressure; $R x=$ prescription.

Figure 1: Adaptive servo-ventilation therapy in sleep apnoea

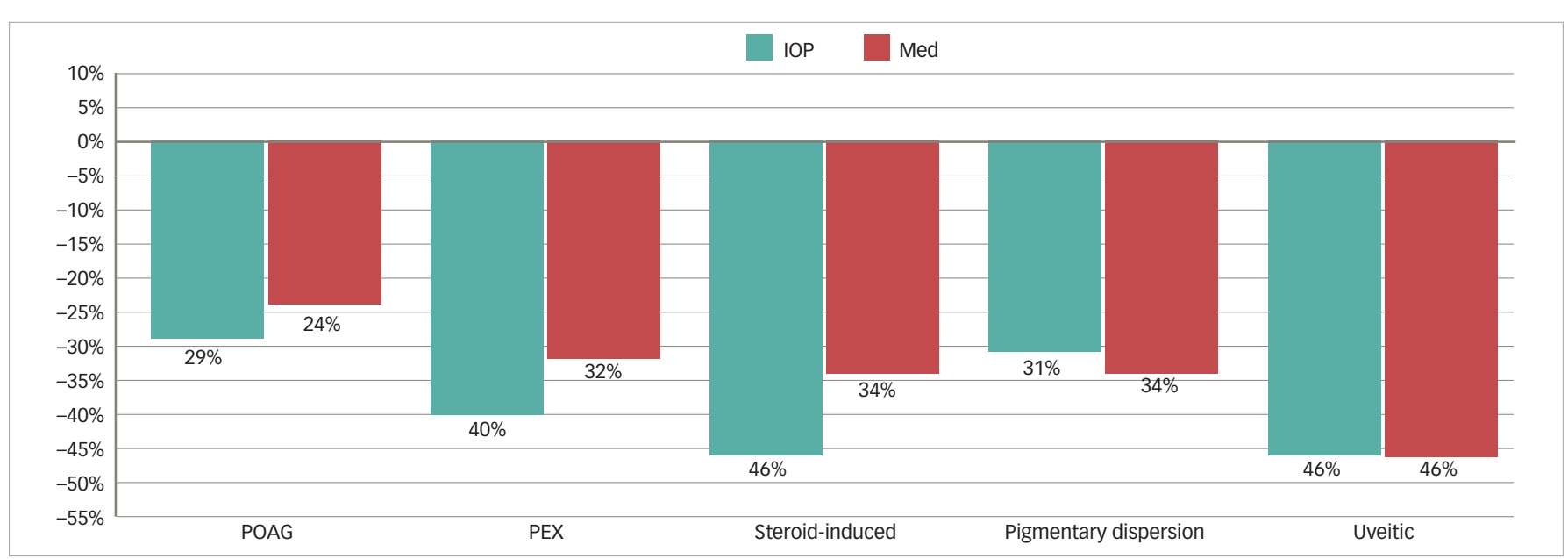

$I O P=$ intraocular pressure; $\mathrm{Med}=$ use of glaucoma medication; $P E X=$ pseudoexfoliating glaucoma; $P O A G=$ primary open angle glaucoma . 
Figure 2: Plots showing reduction in intraocular pressure (A) and glaucoma medication usage (B) in each glaucoma subgroup from baseline to 36 months
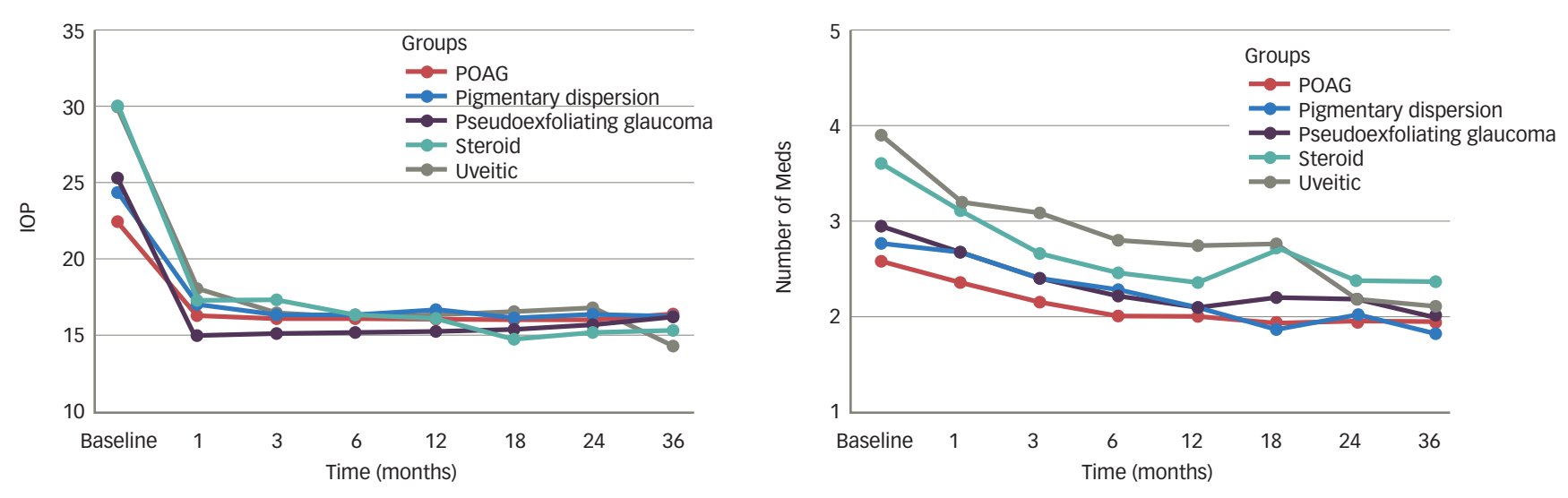

$I O P=$ intraocular pressure; Meds = glaucoma medication usage; $P O A G$ = primary open angle glaucoma.

Figure 3: Survival plot in each glaucoma subgroup from baseline to 36 months

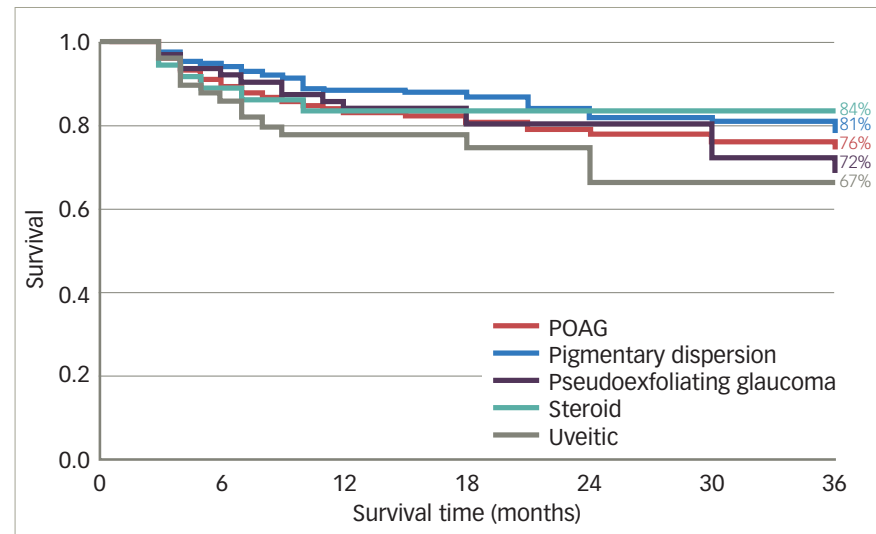

Survival plot, with success defined as post-operative IOP $\leq 21 \mathrm{mmHg}$ with at least $20 \%$ $I O P$ reduction from baseline and no secondary glaucoma surgery.

$I O P=$ intraocular pressure $; P O A G=$ primary open angle glaucoma

Figure 4: Reduction in intraocular pressure and glaucoma medication usage in virgin and previously operated eyes at 36 months

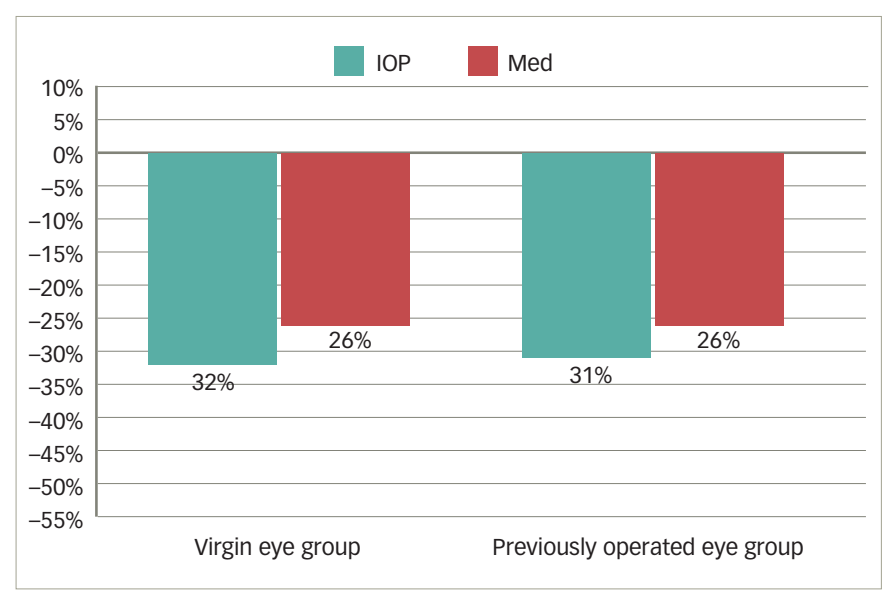

$I O P=$ intraocular pressure; Med = glaucoma medication usage.

higher in the virgin eyes $(78 \%, p<0.01)$ than in the previously-operated group (65\%) (Table 4 and Figure 6). The survival rates for glaucoma subtypes within virgin eyes and the previously-operated eye groups
Table 3: Survival rates at 36 months in glaucoma subgroup

\begin{tabular}{|c|c|c|}
\hline Glaucoma subgroup & Survival at 36 months & $\begin{array}{l}\text { Log-rank test } \\
\text { p-value }\end{array}$ \\
\hline Primary open angle glaucoma & $76 \%$ & \\
\hline Pseudoexfoliating glaucoma & $81 \%$ & 0.159 \\
\hline Pigmentary glaucoma & $71 \%$ & 0.572 \\
\hline Steroid-induced glaucoma & $84 \%$ & 0.317 \\
\hline Uveitic glaucoma & $65 \%$ & 0.185 \\
\hline
\end{tabular}

Log-rank test was used to compare whether the difference between survival curve of primary open angle glaucoma and other glaucoma subtypes was statistically significant. Significance level was set at $p<0.05$.

Table 4: 36-month survival rates in virgin eyes and previously operated eyes

\begin{tabular}{|l|l|l|}
\hline \multicolumn{2}{|c|}{ Survival at 36 months } & $\begin{array}{l}\text { Log-rank test } \\
\text { p-value }\end{array}$ \\
\hline Virgin eye & $78 \%$ & \\
\hline Previously operated eye & $65 \%$ & $<0.01^{*}$ \\
\hline
\end{tabular}

Log-rank test was used to compare whether the difference between survival curve of the virgin eye group and previously operated eye group was statistically significant. Significance level was set at $p<0.05$.

were compared for statistical significance at 36 months as shown in Figure 3. There were no statistically significant differences between subtypes' survival values at 36 months (Table 3).

Reported post-operative complications are summarised in Table 5. Fourteen percent of subjects did not achieve adequate IOP control and required subsequent glaucoma surgery. There were no reported cases of clinically significant hypotony or choroidal effusions.

\section{Discussion}

Over the past several years of experience with trabecular bypass procedures, it has become clear that certain subtypes of glaucoma respond better than others. ${ }^{3}$ For example, it has been previously reported that patients with PEX and steroid-induced glaucoma have exceptionally good outcomes with the trabectome (ab-interno trabeculotomy). ${ }^{4,8,9}$ This observation is reinforced with our findings here and is consistent with the expected outcome, given that the mechanism by which 
Figure 5: Plots showing reduction in intraocular pressure (A) and glaucoma medication usage (B) in virgin and previously operated eyes from baseline to 36 months

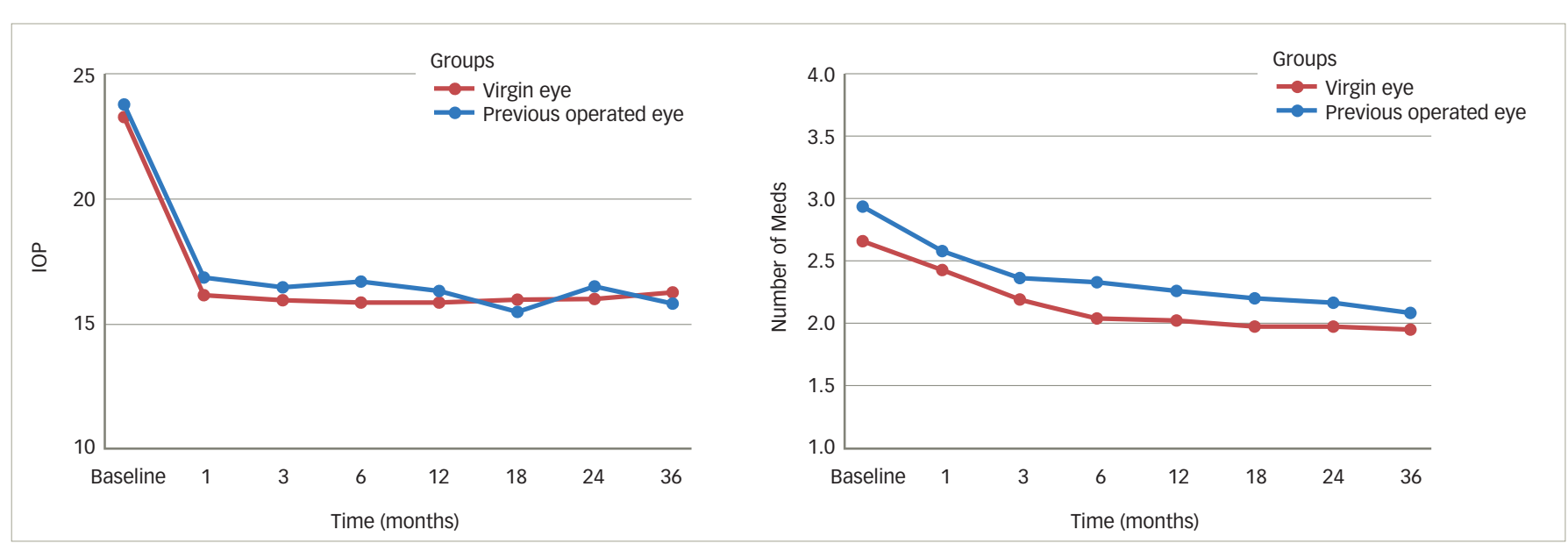

IOP = intraocular pressure; Meds = glaucoma medication usage.

Table 5: Post-operative complications

\begin{tabular}{|c|c|c|c|c|c|c|c|c|}
\hline Post-operative complications & $\begin{array}{l}\text { POAG } \\
n=1,641\end{array}$ & $\begin{array}{l}\text { PEX } \\
n=252\end{array}$ & $\begin{array}{l}\text { Pigmentary } \\
n=69\end{array}$ & $\begin{array}{l}\text { Steroid } \\
\mathrm{n}=38\end{array}$ & $\begin{array}{l}\text { Uveitic } \\
n=51\end{array}$ & $\begin{array}{l}\text { Overall* } \\
n=2,051\end{array}$ & $\begin{array}{l}\text { Virgin eye } \\
n=1,886\end{array}$ & $\begin{array}{l}\text { Previously } \\
\text { operated } \\
\text { eye } \\
n=165\end{array}$ \\
\hline Secondary surgery & $239(14.6 \%)$ & $23(9.1 \%)$ & $11(15.9 \%)$ & $4(10.5 \%)$ & $10(20 \%)$ & $287(14.0 \%)$ & $264(14.0 \%)$ & $23(13.9 \%)$ \\
\hline Sustained hypotony - beyond 30 days post operation & $5(0.3 \%)$ & $0(0.0 \%)$ & $0(0.0 \%)$ & $0(0.0 \%)$ & $0(0.0 \%)$ & $5(0.2 \%)$ & $4(0.2 \%)$ & $1(0.6 \%)$ \\
\hline Hypotony - 1 day post operation & $22(1.3 \%)$ & $2(0.8 \%)$ & $0(0.0 \%)$ & $2(5.3 \%)$ & $1(2.0 \%)$ & $27(1.3 \%)$ & $20(1.1 \%)$ & $7(4.2 \%)$ \\
\hline Infection & $0(0.0 \%)$ & $0(0.0 \%)$ & $0(0.0 \%)$ & $0(0.0 \%)$ & $0(0.0 \%)$ & $0(0.0 \%)$ & $0(0.0 \%)$ & $0(0.0 \%)$ \\
\hline Choroidal haemorrhage & $0(0.0 \%)$ & $0(0.0 \%)$ & $0(0.0 \%)$ & 0 (0.0\%) & 0 (0.0\%) & $0(0.0 \%)$ & 0 (0.0\%) & 0 (0.0\%) \\
\hline
\end{tabular}

*Overall number does not include values from virgin and previously operated eyes. PEX = pseudoexfoliating glaucoma; $P O A G=$ primary open angle glaucoma

Figure 6: Survival plot for virgin versus previously operated eyes from baseline to 36 months

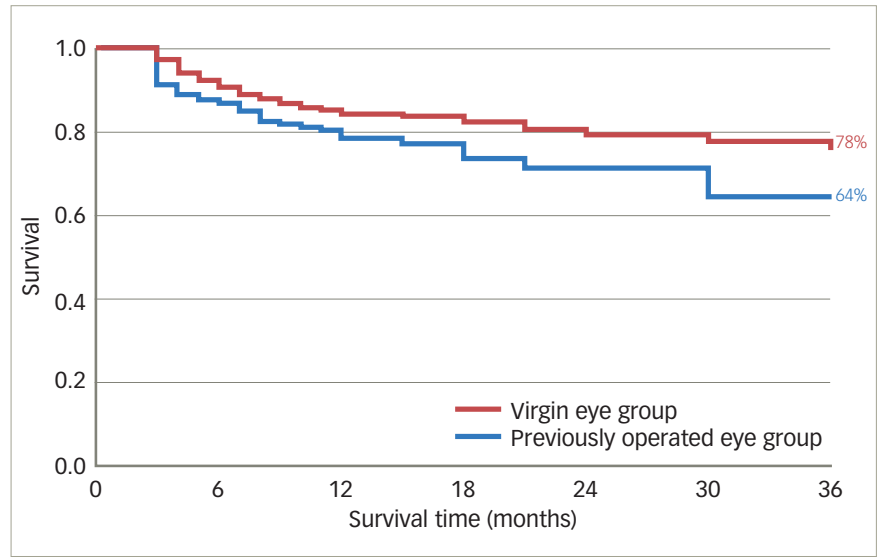

Survival plot, with success defined as post-operative IOP $\leq 21 \mathrm{mmHg}$ with at least $20 \%$ $I O P$ reduction from baseline and no secondary glaucoma surgery. $1 O P=$ intraocular pressure

IOP is elevated in these conditions is a result of increased trabecular resistance. Trabecular bypass procedures which remove a large section of the meshwork restore the flow into Schlemm's canal and normalise IOP in these subcategories of glaucoma. This is in contrast to uveitic glaucoma, where the mechanism of IOP elevation is likely multifactorial; many of these patients exhibit extensive peripheral anterior synechiae, with chronic angle closure contributing a significant degree to the impediment to aqueous outflow. ${ }^{10}$ The observation here that uveitic glaucoma had a trend towards lower success than other subcategories is therefore not surprising. Although this was not statistically significant, $56 \%$ of our subgroup had a successful outcome at 36 months follow up. Interestingly, Anton et al. showed an $87.5 \%$ success rate in trabectome surgery in patients with uveitic glaucoma followed for 1 year. ${ }^{11}$ It is known that these patients tend to have a worse outcome with trabeculectomy as well. ${ }^{12}$ While tube shunt implantations seem to be more effective in this group, this is still a group of patients for which a procedure with safe and consistent outcomes is still lacking. ${ }^{13-5}$

In this study, patients with POAG showed impressive success rates and IOP reductions, but slightly lower than that seen in the PEX group. This can be explained by the fact that POAG represents a heterogeneous group of patients in which impaired downstream and uveoscleral pathways of aqueous egress, as well as IOP-independent mechanisms of optic nerve atrophy, may play a role in the progression of disease. While removing the trabecular meshwork may be effective for the majority of patients in this group, it is not the answer for everybody, as approximately $14 \%$ of patients required secondary surgery from failure to meet IOP goals (Table 5). However, given the excellent safety profile, the trabectome represents an option in which the benefits outweigh the risks, even in patients with refractory disease who have failed other prior surgical interventions. ${ }^{5,6,16}$

In this study, patients with combined cataract surgery were grouped together with patients with trabectome-alone procedures. Several prior 
publications have suggested that combined procedures result in more robust outcomes and higher success rates as compared to stand-alone cases. ${ }^{17}$ There have, however, been several recent reports suggesting that the addition of phacoemulsification does not result in additional IOP reduction. ${ }^{18,19}$ Since we were not intending to once again look at these differences, but rather identify the differences within subcategories of glaucoma, we did not separate out patients with combined trabectome and phacoemulsification. Both the previously-operated eyes and the virgin eye groups had similar numbers of stand-alone versus combined procedures, negating any difference from phacoemulsification in the results.

Another finding demonstrated with these long-term results was that trabectome performed very well following prior incisional surgery, with a success rate of $65 \%$ at 36 months versus $78 \%$ in the virgin eyes. While this outcome suggests a better response in the virgin eyes, it is important to note that our data included eyes with prior vitreoretinal procedures, corneal transplantation and vitrectomies. Again, many of these eyes had mechanisms of glaucoma that were multifactorial and subject to continued insults such as intravitreal steroid injections, the presence of silicone oil and peripheral anterior synechia formation. A recent report by Wecker et al. looked at trabectome outcomes following failed trabeculectomy and found promising success rates, concluding that this could be considered a valuable procedure following failed trabeculectomy. ${ }^{20}$ Another study found that prior failed tube shunt implantation did not decrease the efficacy of trabectome surgery. ${ }^{21}$ Finally, a study based in Europe by Widder et al. concluded that prior tube or trabeculectomy surgery did not affect the outcome of subsequent trabectome procedures. ${ }^{22}$ Collectively, this body of evidence supports the use of the trabectome in these challenging and refractory cases.

Additionally, several recent publications showed no difference in success rates between patients with mild disease versus severe disease based on visual field loss and optic atrophy. ${ }^{23-25} \mathrm{~A}$ recent study by Ahmed et al. demonstrated that 12-month success rates of patients with mild disease was $86 \%$ as compared to $83 \%$ for those with moderate/severe disease. ${ }^{25}$ This challenges our traditional thinking of considering MIGS only in early to moderate disease. Indeed, some more recently approved MIGS implants such as the Cypass ${ }^{\circledR}$ (Alcon, Fort Worth, TX, US) and the iStent are currently only approved for early to moderate glaucoma. As a result, MIGS surgery is typically positioned as an early intervention and not routinely employed in latestage cases. Several dozen publications on the trabectome in various disease states, in the hands of different surgeons and with numerous other ocular comorbidities, all conclude that IOP following trabectome typically stabilises in the mid-teens range..$^{5,26,27}$ These results support the consideration of the trabectome anywhere along the arc of disease where IOP in the mid-teens would be acceptable.

There are several limitations to this study which bear mention. Firstly, this dataset represents the learning curve of many new MIGS surgeons. Presumably, the results here may be poorer than in cases of experienced surgeons, but that is uncertain. Additionally, the surgeons voluntarily update the results of their subjects over time. This may induce reporting bias to favour reporting of successful outcomes over poorer ones. Also, these surgeons are mainly referral physicians that refer the patients back to the comprehensive ophthalmologist once they are stable. Therefore, they may not have data on the successful patients years after treatment, but will more likely see the failures referred back. This may result in longer-term data on the failures as opposed to the longer-term successes. Nonetheless, this dataset represents the largest collection of information on a newer technology with the longest follow-up period available and therefore still can yield valuable insight.

As glaucoma is a long-term disease, logic dictates that treatments with long-term proven safety and efficacy be preferentially employed over procedures where the efficacy significantly wanes over time. As a result, many glaucoma surgeons have taken a more measured approach to adoption of these newer techniques. At this point in time, with over a decade of robust experience, surgeons can utilise these data to help predict outcomes in specific subsets of disease to more confidently assign treatments in a tailored fashion to individual patients. Given the well-established long-term safety profile of the trabectome and encouraging efficacy results across the spectrum of disease severity, this study shows that it can be considered as a valuable surgical option even in patients with refractory disease. $\square$
1. Minckler D, Baerveldt $G$, Ramirez MA, et al. Clinical results with the trabectome, a novel surgical device for treatment of openangle glaucoma. Trans Am Ophthalmol Soc. 2006;104:40-50.

2. Minckler D, Mosaed S, Dustin L, et al. Trabectome (trabeculectomy-internal approach): additional experience (trabeculectomy-internal approach): additional exp 2008:106:149-60.

3. Jordan JF, Wecker T, van Oterendorp C, et al. Trabectome surgery for primary and secondary open angle glaucomas Graefes Arch Clin Exp Ophthalmol. 2013;251:2753-60.

4. Mosaed S. The first decade of global trabectome outcomes. European Ophthalmic Review. 2014;8:113-9.

5. Mizoguchi T, Nishigaki S, Sato T, et al. Clinical results of trabectome surgery for open-angle glaucoma. Clin Ophthalmol. 2015;9:1889-94.

6. Kaplowitz K, Bussel II, Honkanen R, et al. Review and meta-analysis of ab-interno trabeculectomy outcomes. Br J Ophthalmol. 2016;100:594-600.

7. Gedde SJ, Schiffman JC, Feuer WJ, et al. Treatment outcomes in the Tube Versus Trabeculectomy (TVT) study after five years of the Tube Versus Trabeculectomy (TVT) study after fol

8. Ting LL, Damji KF, Stiles MC. Ab interno trabeculectomy: outcomes in exfoliation versus primary open-angle glaucoma. $J$ Cataract Refract Surg. 2012;38:315-23.

9. Ngai P, Kim G, Chak $G$, et al. Outcome of primary trabeculotomy ab interno (Trabectome) surgery in patients with steroidinduced glaucoma. Medicine. 2016;95:e5383.

10. Sng CC, Barton K. Mechanism and management of angle closure in uveitis. Curr Opin Ophthalmol. 2015;26:121-7.
11. Anton $A$, Heinzelmann $S$, NeB T, et al. Trabeculectomy ab interno with the Trabectome ${ }^{\oplus}$ as a therapeutic option for uveitic secondary glaucoma. Graefes Arch Clin Exp Ophthalmol. 2015:253:1973-8.

12. Noble J, Derzko-Dzulynsky L, Rabinovitch T, Birt C. Outcome of trabeculectomy with intraoperative mitomycin $\mathrm{C}$ for uveitic glaucoma. Can 1 Ophthalmol. 2007:42:89-94.

13. William A, Spitzer MS, Doycheva D, et al. Comparison of ab externo trabeculotomy in primary open-angle glaucoma and uveitic glaucoma: long-term outcomes. Clin Ophthalmol. 2016;10:929-34.

14. Almobarak FA, Alharbi AH, Morales J, Aljadaan I. Intermediate and long-term outcomes of mitomycin C-enhanced trabeculectomy as a first glaucoma procedure in uveitic glaucoma. J Glaucoma. 2017;26:478-85.

15. Kwon HJ, Kong YX, Tao LW, et al. Surgical outcomes of trabeculectomy and glaucoma drainage implant for uveitic glaucoma and relationship with uveitis activity. Clin Exp Ophthalmol. 2017:45:472-80.

16. Dang YL, Cen YJ, Hong Y, et al. Safety and efficiency of trabectome-mediated trabecular meshwork ablation for Chinese glaucoma patients: a two-year, retrospective, Chinese glaucoma patients: a two-year, retrospective,

17. Okeke CO, Miller-Ellis E, Rojas M. Trabectome success factors. Okeke CO, Miller-Ellis E, Rojas
Medicine. 2017;96:e7061

18. Neiweem AE, Bussel II, Schuman JS, et al. Glaucoma surgery calculator: limited additive effect of phacoemulsification on intraocular pressure in ab interno trabeculectomy. PLOS One. 2016;11:e0153585
19. Parikh HA, Bussel II, Schuman IS, et al. Coarsened exact matching of phaco-trabectome to trabectome in phakic patients: lack of additional pressure reduction from phacoemulsification. PLOS One. 2016;11:e0149384.

20. Wecker T, Neuburger M, Bryniok $L$, et al. Ab interno trabeculectomy with the Trabectome as a valuable therapeutic option for failed filtering blebs. J Glaucoma. 2016;25:758-62.

21. Mosaed S, Chak G, Haider A, et al. Results of trabectome surgery following failed glaucoma tube shunt implantation: cohort study. Medicine. 2015;94:e1045

22. Widder RA, Dietlein TS. Surgical options before and after trabectome surgery: impact of previous surgeries, possibilities of revision surgery and complication management. Ophthalmologe. 2016;113:914-7. [Article in German].

23. Dang Y, Roy P, Bussel II, et al. Combined analysis of trabectome and phaco-trabectome outcomes by glaucoma severity. Version 2. F1000Res. 2016;5:762.

24. Loewen RT, Roy P, Parikh HA, et al. Impact of a glaucoma severity index on results of trabectome surgery: larger pressure reduction in more severe glaucoma. PLOS One. 2016:11:00151926.

25. Ahmed SF, Bhatt A, Schmutz M, Mosaed S. Trabectome outcomes across the spectrum of glaucoma disease severity. Graefes Arch Clin Exp Ophthalmol. 2018; doi: 10.1007/s00417018-4023-8 [Epub ahead of print].

26. Yildirim Y, Kar T, Duzgun E, et al. Evaluation of the long-term results of trabectome surgery. Int Ophthalmol. 2016;36:719-26.

27. Vinod K, Gedde SJ. Ab interno trabeculectomy: patient selection and perspectives. Clin Ophthalmol. 2016;10:1557-64. 